\title{
INELEGIBILIDADE EM CASO DE RENÚNCIA A MANDATO ELETIVO E O CASO DO EX-SENADOR JOAQUIM RORIZ
}

\author{
FELIPE ANTÔNIO DE CASTRO BEZERRA MORAIS MELO \\ Advogado, mestrando em Direito Constitucional Público e \\ Teoria Política pela Universidade de Fortaleza (UNIFOR) \\ e pós-graduando em Direito e Processo Eleitoral \\ pela Universidade de Fortaleza (UNIFOR).
}

YURY GAGARY ARAÚJO MESQUITA Advogado, mestrando em Resolução de Conflitos e Mediação pela Universidade Europeia do Atlântico e pós-graduando em Direito e Processo Eleitoral pela Universidade de Fortaleza (UNIFOR).

Resumo: O instituto jurídico da inelegibilidade pode ser considerado, em tese, como um obstáculo ao livre exercício da capacidade eleitoral passiva, ou seja, um impedimento à possibilidade de um cidadão receber votos, tendo em vista que seu objetivo é exatamente proteger a probidade das eleições, a moralidade do exercício do mandato e a legitimidade contra a influência do destruidor poder econômico ou o abuso do exercício de função, tanto na Administração Pública Direta, quanto na Indireta. A inelegibilidade em caso de renúncia ao mandato eletivo é classificada como infraconstitucional, pois está prevista apenas na Lei Complementar n. ${ }^{\circ}$ 64/90, alterada em 2010 pela Lei da Ficha Limpa. Portanto, este artigo científico se propõe a analisar, de maneira crítica, o caso do exsenador do Distrito Federal, Joaquim Roriz. Desse modo, considerando a consulta realizada à doutrina nacional e estrangeira, a metodologia será do tipo bibliográfica. Quanto à natureza e fins da metodologia, será do tipo, respectivamente, qualitativa e exploratória.. Logo, o objetivo geral deste trabalho é fazer um estudo acurado do instituto da inelegibilidade, enquanto o objetivo específico é demonstrar que a inelegibilidade em caso de renúncia de mandato contribuem para o combate à corrupção no Brasil. 
Palavras-chave: Direito Eleitoral. Inelegibilidade. Lei da Ficha Limpa. Soberania popular. Renúncia de mandato.

\section{INTRODUÇÃO}

Inicialmente, vale registrar que a Lei Complementar n. ${ }^{\circ}$ 135/2010 ("Lei da Ficha Limpa"), oriunda de uma iniciativa popular, alterou significativamente a Lei Complementar n. ${ }^{\circ}$ 64/99, conhecida como "Lei das Inelegibilidades".

Assim, algumas das discussões contidas neste artigo científico consistirão no esclarecimento sobre as consequências destas alterações na Lei de Inelegibilidades e a restrição no exercício da capacidade eleitoral passiva, ou seja, no direito de receber votos.

Sabe-se que havia uma prática muito comum entre os políticos de renunciar ao mandato eletivo em caso de oferecimento de representação que pudesse ocasionar uma eventual cassação de mandato, sem que esta atitude acarretasse em inelegibilidade. Porém, percebe-se que, após a reforma trazida pela Lei da Ficha Limpa, já é possível a ocorrência em uma situação como esta, em decorrência da inserção da alínea " $\mathrm{k}$ " ao inciso I do artigo $1^{\circ}$ da Lei Complementar n. ${ }^{\circ}$ 64/90 (BRASIL, 1990).

Além disso, após a análise acerca da inelegibilidade em caso de renúncia ao mandato eletivo, este trabalho também estudará o caso do ex-Senador do Distrito Federal Joaquim Domingos Roriz, tendo em vista que foi um dos mais emblemáticos casos no país após a vigência da Lei da Ficha Limpa.

Desse modo, para uma melhor compreensão sobre o instituto desta inelegibilidade, será necessário o estudo sobre o entendimento jurisprudencial do STF e TSE, a Constituição Federal, o Código Eleitoral, a Lei de Inelegibilidades e a Lei da Ficha Limpa.

Partindo-se do exposto, o objetivo geral desta pesquisa será fazer uma anamnese do instituto jurídico da inelegibilidade. Desse modo, o objetivo específico é demonstrar que a inelegibilidade em caso de renúncia de mandato contribui para o combate à corrupção no Brasil.

Dessa forma, considerando a consulta realizada à doutrina nacional e estrangeira, a metodologia será do tipo bibliográfica. Quanto à natureza e fins da metodologia, será do tipo, respectivamente, qualitativa e exploratória. 
No primeiro tópico será feita uma análise sobre a Lei da Ficha Limpa, isto é, como surgiu, sua constitucionalidade e suas principais alterações realizadas na Lei Complementar n. o 64/1990 (“Lei de Inelegibilidades”).

No segundo tópico, estudar-se-á sobre o instituto jurídico da inelegibilidade, bem como seu conceito e algumas de suas classificações. Dar-se-á uma atenção, especialmente, na inelegibilidade em caso de renúncia ao mandato eletivo.

No terceiro tópico, por fim, será analisado o caso do ex-Senador do Distrito Federal Joaquim Domingos Roriz, estudando-se os fundamentos utilizados para que ele fosse considerado inelegível.

\section{A CONSTITUCIONALIDADE DA LEI DA FICHA LIMPAE SUAS PRINCIPAIS ALTERAÇÕES NA LEI DAS INELEGIBILIDADES}

A Lei Complementar n. ${ }^{\circ}$ 135/2010, conhecida popularmente como "Lei da Ficha Limpa" é fruto de um anseio da população brasileira para moralizar e tornar as eleições imunes de candidatos desonestos, assim, a veracidade desta afirmação é comprovada pelo fato de que tal lei é uma das quatro que foram criadas por inciativa popular em toda história de nosso ordenamento jurídico.

Vale registrar que o maior fito da Lei de Ficha Limpa foi alterar a Lei Complementar n. ${ }^{\circ}$ 64/90, conhecida como "Lei de Inelegibilidades" para que diversas novas hipóteses de inelegibilidade fossem acrescidas ao antigo ordenamento jurídico e, consequentemente, a probabilidade de um político corrupto poder exercer o mandato ficasse consideravelmente menor.

Djalma Pinto e Elke Petersen lecionam que a mobilização popular para a criação da Lei da Ficha Limpa foi iniciada em abril de 2008, quando o Movimento de Combate à Corrupção Eleitoral (MCCE) começou a colher assinaturas para a apresentação do projeto de lei à Câmara dos Deputados, porém, no decorrer no tempo, pode-se afirmar que várias outras instituições contribuíram para o surgimento de tal inovação legislativa, como, por exemplo a Ordem dos Advogados do Brasil (OAB) e a Conferência Nacional dos Bispos do Brasil (2014, p.1).

Conforme dados extraídos do sítio eletrônico do próprio MCCE, depois de um ano e meio de campanha, após o devido preenchimento dos 
requisitos estabelecidos no artigo 61 da Constituição Federal, foi entregue ao, até então, Presidente da Câmara dos Deputados, Michel Temer, o projeto de lei da Ficha Limpa, com um milhão e trezentas mil assinaturas presenciais. Logo, ficou clara a expressiva vontade do povo brasileiro por um maior controle às candidaturas nas eleições futuras. (2016, online)

Todavia, cumpre esclarecer que, não obstante o enorme clamor social, a Lei da Ficha Limpa demorou mais de 8 (oito) meses para ser aprovada na Câmara dos Deputados e no Senado Federal antes de ser enviada ao, à época, Presidente da República, o senhor Luiz Inácio Lula da Silva, o que fortalece, ainda mais, a ideia de um Poder Legislativo burocrático, moroso e ineficaz em nosso país.

Registre-se que foram ajuizadas três ações no STF com o fito de analisar a constitucionalidade da Lei da Ficha Limpa, especificadamente, nas ADCs n. ${ }^{\circ} 29$, n. 30 e na ADI n..$^{\circ}$ 4.578. Vale ressaltar o posicionamento do ministro Joaquim Barbosa nestas ações anteriormente citadas, um dos grandes responsáveis pela declaração de constitucionalidade da Lei da Ficha Limpa, abaixo exposto:

Nessa ordem de ideias, entendo que os critérios eleitos pelo legislador complementar, critérios estes, vale frisar, nascidos e fomentados no seio da nossa sociedade, defendidos e exigidos por movimento social expressivo, estão em perfeita harmonia com a Lei Maior. [...] Assim, como diversas vezes já afirmei nesse Plenário, eu analiso a Lei Complementar n. ${ }^{\circ} 135 / 2010$, sob a ótica da valorização da moralidade e da probidade no trato da coisa pública, sob a ótica da proteção ao interesse público, e não para o fim de proteção preferencial aos interesses puramente individuais e privados. $\mathrm{Na}$ ponderação entre os valores concernentes aos direitos políticos individuais e os valores referentes aos direitos políticos em sua dimensão coletiva, os primeiros devem ceder pontualmente em face de um princípio de maior envergadura constitucional, que é a própria democracia e os seus mecanismos operativos. (BRASIL, 2016)

Com a vigência da Lei da Ficha Limpa, são considerados inelegíveis não apenas os condenados em sentença criminal transitada em julgado, mas também aqueles que forem condenados por órgão judicial colegiado, fato este que, segundo uma corrente minoritária na doutrina, prejudicaria o princípio da presunção de inocência. 
Entretanto, sabe-se que a inelegibilidade não tem caráter de pena, logo, o fato de o legislador ter considerado inelegível o cidadão condenado por órgão judicial colegiado, antes mesmo do trânsito em julgado, não viola o princípio da presunção de inocência.

Importante registrar a elucidação, a respeito deste assunto, de Djalma Pinto e Elke Petersen (2014, p.24):

A propósito, cabe um esclarecimento: não se deve confundir decisões colegiadas com decisões de $2^{\circ}$ grau ou grau de recurso, pois a Lei Complementar n. ${ }^{\circ}$ 135/2010 prevê que o indivíduo ficará inelegível caso tenha uma decisão de órgão judicial colegiado contra sua pessoa, prevista em uma das hipóteses da Lei de Inelegibilidades, que não necessariamente "de $2^{\circ}$ grau".

Dessa forma, exemplificadamente, entende-se que caso um indivíduo seja condenado pelo Tribunal do Júri, mesmo em um julgamento de primeira instância, já será considerado inelegível, tendo em vista que se trata de um órgão judicial colegiado.

Assim, ressalte-se que a Lei Complementar n. ${ }^{\circ}$ 135/2010, quando acrescentou novas hipóteses deinelegibilidade ao nosso ordenamento jurídico, além de ter aumento para oito anos o prazo de incidência deste instituto, visou dificultar o acesso do poder aos maus gestores, desrespeitadores das leis, comprovadamente julgados infratores e aos corruptos. (BRASIL, 2010)

Em resumo, pode-se afirmar que a Lei da Ficha Limpa surgiu em um contexto histórico de amadurecimento da democracia no Brasil, onde a sociedade, cada vez mais, exige uma maior probidade e respeito dos políticos para com a gestão dos recursos públicos.

Logo, ainda é necessária uma reflexão sobre o atual momento político do Brasil, tendo em vista que, apesar de alguns avanços, como a vigência da Lei da Ficha Limpa, sabe-se que o Brasil ainda está longe de ser um país modelo na gestão de recursos públicos, haja vista o recorrente surgimento de escândalos de corrupção envolvendo políticos brasileiros e acusações de abuso de poder econômico nas campanhas eleitorais.

No próximo tópico será estudado o instituto da inelegibilidade em caso de renúncia ao mandato eletivo. 


\section{O INSTITUTO JURÍDICO DA INELEGIBILIDADE EM CASO DE RENÚNCIA AO MANDATO ELETIVO}

O instituto da inelegibilidade pode ser considerado com um obstáculo ao exercício da capacidade eleitoral passiva, ou seja, um óbice à possibilidade de um cidadão ser votado, tendo em vista que seu objetivo é exatamente proteger a probidade das eleições, a moralidade do exercício do mandato e legitimidade contra a influência do devassador poder econômico ou abuso do exercício de função, tanto na Administração Pública Direta, quanto na Indireta.

Dessa forma, a ausência de apenas um requisito de elegibilidade já acarreta na inelegibilidade, independentemente de manifestação do partido político a que o candidato é filiado, ou de manifestação do próprio candidato.

A inelegibilidade possui um duplo fundamento, tendo em vista que, por um lado, há a "inelegibilidade sanção" ou cominada, quando o agente político pratica abuso de poder e, consequentemente, é sancionado; ademais, existe também a inelegibilidade conhecida como originária ou inata, quando é declarada no momento do registro da candidatura, em decorrência do descumprimento dos requisitos mínimos para que fosse concretizado tal ato.

O conceito de inelegibilidade é lecionado por Manoel Gonçalves Ferreira Filho (2008, p.118):

Inelegibilidade é uma medida destinada a defender a democracia contra possíveis e prováveis abusos. Em sua origem, na Constituição de 1934, aparecia ela como medida preventiva, ideada para impedir que principalmente os titulares de cargos públicos executivos, eletivos ou não, se servissem de seus poderes para serem reconduzidos ao cargo, ou para conduzirem-se a outro, assim como para eleger seus parentes. Para tanto, impedia suas candidaturas, assim como a de cônjuge ou parentes, por um certo lapso de tempo (art.112).

A respeito deste instituto, afirma José Jairo Gomes (2014, p. 169):

[...] é lícito asseverar que a inelegibilidade apresenta duplo fundamento. De um lado, pode ser constituída pela aplicação de uma sanção. De outro, pode ser declarada no processo de registro de candidatura, em razão da não adequação da situação do cidadão ao 
regime jurídico-eleitoral em vigor. Cada um desses casos submete-se a regramento próprio.

Ressalte-se o posicionamento, sob o enfoque constitucional, de José Afonso da Silva (2008, p. 390), sobre a inelegibilidade:

Inelegibilidade revela impedimento à capacidade eleitoral passiva (direito de ser votado). Obsta, pois, à elegibilidade. Não se confunde com a inalistabilidade, que é o impedimento à capacidade eleitoral ativa (direito de ser eleitor), nem com incompatibilidade, impedimento ao exercício do mandato depois de eleito.

Utilizando o critério hierárquico, percebe-se que a inelegibilidade em caso de renúncia ao mandato eletivo pode ser classificada como infraconstitucional, tendo em vista que está prevista no artigo $1^{\circ}, \mathrm{I}$, "k", da Lei Complementar n. ${ }^{\circ}$ 64/90, senão vejamos:

[...] O Presidente da República, o Governador de Estado e do Distrito Federal, o Prefeito, os membros do Congresso Nacional, das Assembleias Legislativas, da Câmara Legislativa, das Câmaras Municipais, que renunciarem a seus mandatos desde o oferecimento de representação ou petição capaz de autorizar a abertura de processo por infringência a dispositivo da Constituição Federal, da Constituição Estadual, da Lei Orgânica do Distrito Federal ou da Lei Orgânica do Município, para as eleições que se realizarem durante o período remanescente do mandato para o qual foram eleitos e nos 8 (oito) anos subsequentes ao término da legislatura;

Desse modo, conforme exposto acima, cumpre esclarecer que a inelegibilidade em estudo tem duração no período restante do mandato para qual o político foi eleito, bem como nos oito anos subsequentes ao término da legislatura.

O doutrinador José Jairo Gomes entende que só a renúncia ao mandato eletivo após o oferecimento, ao órgão competente, de representação ou petição aptos a ensejarem a instauração de processo na Casa Legislativa tem o condão de gerar a mencionada inelegibilidade do renunciante. (2014, p.193).

Vale salientar que o $\ 5^{\circ}$ do artigo $1^{\circ}$ da Lei das Inelegibilidades traz uma exceção, abaixo exposta: 
$\int 5^{\circ}$ A renúncia para atender à desincompatibilização com vistas a candidatura a cargo eletivo ou para assunção de mandato não gerará a inelegibilidade prevista na alínea $\mathrm{k}$, a menos que a Justiça Eleitoral reconheça fraude ao disposto nesta Lei Complementar.

Assim, resta claro que esta hipótese de inelegibilidade não incidirá em caso de renúncia para fins de desincompatibilização, isto é, trata-se de uma relevante exceção.

Logo, após uma análise acurada deste instituto, pode-se afirmar que a inelegibilidade em caso de renúncia ao mandato eletivo foi inserida em nosso ordenamento jurídico com o objetivo de cessar uma atitude que era comum entre os políticos, de renunciar ao cargo para evitar a cassação, sem que isso acarretasse em nenhum tipo de inelegibilidade, ou seja, antes desta alteração, eles já poderiam se candidatar novamente nas próximas eleições.

No próximo tópico será estudado, especificadamente, o caso do exSenador da República Joaquim Domingos Roriz.

\section{O CASO DO EX-SENADOR JOAQUIM DOMINGOS RORIZ}

Joaquim Domingos Roriz, é popularmente conhecido no CentroOeste do país, onde foi governador do Distrito Federal por quatro mandatos e, por último, senador, pelo Partido do Movimento Democrático Brasileiro (PMDB).

Ocorre que, no ano de 2006, se candidatou ao Senado pelo PMDB e foi eleito em $1^{\circ}$ de outubro do mesmo ano. No ano subsequente, assumiu o cargo em $1^{\circ}$ de fevereiro de 2007 e logo após, renunciou em 4 de julho do mesmo ano, após se envolver no escândalo do Banco Regional de Brasília (BRB), visando não sofrer um processo de cassação e ficar inelegível pelo período de 8 anos.

No entanto, ao se candidatar no ano de 2010, ao governo do Distrito Federal, Joaquim Roriz teve sua candidatura impugnada pelo Ministério Público, e pelos demais partidos e coligações que concorriam no referido pleito. (SANTOS, 2010, online)

Anote-se que, em 2010, se existia a celeuma no tocante a aplicação ou não da Lei Complementar 135/2010 nas eleições do ano supra, o Supremo 
Tribunal Federal avaliou esta discussão e entendeu pela aplicação da Lei da Ficha Limpa no pleito do referido ano, bem como entendeu que a lei se aplicava para condenações anteriores a sua vigência.

Como já evidenciado, a Lei da ficha limpa impede a candidatura de políticos condenados em decisões colegiadas e que renunciaram ao mandato eletivo para escapar de processo de cassação.

O Tribunal Regional Eleitoral do Distrito Federal (TRE/DF) ao analisar o pedido de impugnação de registro de candidatura de Roriz, indeferiu o registro, pois entendeu que, na época, o então Senador renunciou do cargo tão apenas no intuito de se livrar de uma cassação, e, por isso, teria incorrido na conduta prevista no $1^{\circ}$, I, "k", da Lei Complementar n. ' 64/90. (SANTOS, 2010, online)

Roriz recorreu da decisão ao Tribunal Superior Eleitoral (TSE) sob o argumento de que, no momento da renúncia, não existia nenhum processo contra ele. Contudo, o Ministério Público sustentou que o ex-senador haveria renunciado porque sabia da existência da denúncia contra ele e, por consequência, da abertura de um processo de cassação. O TSE, ao apreciar o recuso, manteve a decisão do TRE/DF. (COELHO, 2010, online)

Joaquim Roriz, não satisfeito, recorreu ao Supremo Tribunal Federal, que, por seis votos a quatro, declarou extinto o processo, fundamentando-se que a desistência da candidatura do político fez com a que a ação perdesse o objeto. (HAIDAR, 2010, online)

Observa-se, então, que o ex-Senador, em razão da vigência da Lei da Ficha Limpa, por força de decisão colegiada, ficou inelegível, tendo sido negado seu pedido de registro de candidatura ao cargo de Governador do Distrito Federal no ano de 2010.

\section{CONCLUSÕES}

Conclui-se, então, após uma análise do assunto aqui exposto, que a Lei da Ficha Limpa contribuiu para a moralização da política ao aumentar as hipóteses de inelegibilidade, restringindo a capacidade eleitoral passiva de eventuais candidatos que não estão aptos a concorrer a algum cargo eletivo. 
Investigou-se que a Lei da Ficha Limpa é, sim, constitucional, tendo em vista que está de acordo com as premissas do Estado Democrático de Direito, bem como com os princípios gerais da Administração Pública, estabelecidos no artigo 37 da Constituição Federal.

Após um acurado estudo feito acima, pode-se afirmar que a inelegibilidade em caso de renúncia a mandato eletivo coibiu uma prática espúria que era comum aos políticos, de renunciar ao cargo para evitar a cassação, sem que isso resultasse em inelegibilidade.

Neste artigo científico, analisou-se o primeiro caso deste tipo específico de inelegibilidade no país após a alteração legislativa, do ex-senador Joaquim Roriz, que se tornou inelegível por renunciar ao mandato após saber da denúncia contra sua pessoa, e a consequente abertura de processo de cassação de mandato.

Logo, pode-se afirmar que a inelegibilidade em caso de renúncia a mandato eletivo, prevista no artigo 1º, I, "k", da Lei Complementar n. ${ }^{\circ}$ 64/90, contribui para a moralização e para o combate à corrupção na política brasileira.

\section{REFERÊNCIAS}

BRASIL. Constituição (1998). Constituição da República Federativa do Brasil. Brasília: DF, Senado, 1988. Disponível em: <http://www.planalto.gov.br/ ccivil_03/constituicao/constituicao.htm> Acesso: 05 maio 2016.

. Lei n. ${ }^{\circ}$ 4.737, de 15 de julho de 1965. Institui o Código Eleitoral. Diário Oficial da União, Brasília, DF, 7 de junho de 1965. Disponível em: <http://www.planalto.gov.br/ccivil_03/leis/14737.htm> . Acesso em: 04 maio 2016.

. Lei Complementar n. ${ }^{\circ}$ 64, de 18 de maio de 1990. Estabelece, de acordo com o art. 14, \ $9^{\circ}$ da Constituição Federal, casos de inelegibilidade, prazo de cessação, e determina outras providências. Diário Oficial da União, Brasília, DF, 21 de maio de 1990. Disponível em: <http://www.planalto. gov.br/ccivil_03/leis/lcp/lcp64.htm>. Acesso em: 04 maio 2016. 
. Lei Complementar n. ${ }^{\circ}$ 135, de 4 de junho de 2010. Altera a Lei Complementar n. ${ }^{\circ}$ 64, de 18 de maio de 1990, que estabelece, de acordo com o $\int 9^{\circ}$ do art. 14 da Constituição Federal, casos de inelegibilidade, prazos de cessação, e determina outras providências, para incluir hipóteses de inelegibilidade que visam a proteger a probidade administrativa e a moralidade no exercício do mandato. Diário Oficial da União, Brasília, DF, 7 de junho de 2010. Disponível em: < http:/ / www.planalto.gov.br/ccivil_03/ leis/lcp/lcp135.htm>. Acesso em: 05 maio 2016.

- Supremo Tribunal Federal. Ação Declaratória de Constitucionalidade n. ${ }^{\circ}$ 29. DJe 29/6/2012. Disponível em: <http:/ redir.stf.jus.br/paginadorpub/ paginador.jsp?doc'TP=TP\&docID=2243342> . Acesso em: 02 maio 2016.

- Ação Declaratória de Constitucionalidade n. 30 . DJe 29/6/2012. Disponível em: <http:/redir.stf.jus.br/paginadorpub/paginador. jsp?doc'TP=TP\&docID=2257978 > . Acesso em: 03 maio 2016.

- Ação Declaratória de Inconstitucionalidade n. ${ }^{\circ}$.578/DF. DJe 26/6/2012. Disponível em: <http:/redir.stf.jus.br/paginadorpub/paginador. jsp?doc'TP=TP\&docID=2257978> . Acesso em: 05 maio 2016.

- Tribunal Superior Eleitoral. Recurso Ordinário n. ${ }^{\circ}$ 15.429/DF. DJe 11/09/2014. Disponível em: <http://inter03. ts e.jus.br/InteiroTeor/pesquisa/action GetBinary. do\&protocolo $=230852014 \&$ noCache $=0.8396245657932013>$ Acesso em: 05 maio 2016.

COELHO, Mário. TSE mantém cassação de Joaquim Roriz. 2010. Disponível em: <http://congressoemfoco.uol.com.br/noticias/tse-mantem-cassacaode-joaquim-roriz/>. Acesso em: 30 ago. 2017.

FERREIRA FILHO, Manoel Gonçalves. Curso de Direito Constitucional. 34 ed. rev. e atual. São Paulo: Saraiva, 2008.

GOMES, José Jairo. Direito Eleitoral. 10. ed. rev. e atual. e ampl. São Paulo: Atlas, 2014.

HAIDAR, Rodrigo. Extinta ação de Roriz contra a Ficha Limpa no STF. 2010. Disponível em: <http://www.conjur.com.br/2010-set-29/stf-declaraextinta-acao-roriz-lei-ficha-limpa>. Acesso em: 30 ago. 2017. 


\section{MOVIMENTO DE COMBATE À CORRUPÇÃO ELEITORAL.}

Campanha ficha limpa: uma vitória da sociedade. Disponível em: <http://www. mcce.org.br/site>. Acesso em: 04 maio 2016.

PINTO, Djalma; PETERSEN, Elke Braid. Comentários à Lei da Ficha Limpa. São Paulo: Atlas, 2014.

SANTOS, Débora. TSE nega registro de candidatura de Joaquim Roriz: Exgovernador do DF foi barrado pela ficha limpa; cabe recurso ao STF. Em 2007, Roriz renunciou a mandato de senador para escapar de cassação. 2010. Disponível em: <http://g1.globo.com/especiais/eleicoes-2010/ noticia/2010/08/tse-nega-registro-de-candidatura-de-joaquim-roriz. html>. Acesso em: 30 ago. 2017.

SILVA, José Afonso da. Curso de Direito Constitucional Positivo. 30. ed. São Paulo: Malheiros, 2008. 